\title{
Pathogenic Cav3.2 channel mutation in a child with primary generalized epilepsy
}

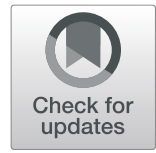

Ivana A. Souza', Maria A. Gandini ${ }^{1}$, Fang-Xiong Zhang ${ }^{1}$, Wendy G. Mitchell2 ${ }^{2}$, Joyce Matsumoto ${ }^{3}$, Jason Lerner ${ }^{3}$, Tyler Mark Pierson ${ }^{4,5,6}$ and Gerald W. Zamponi ${ }^{1^{*}}$ (D)

\begin{abstract}
Two paternally-inherited missense variants in $\mathrm{CACNA} 1 \mathrm{H}$ were identified and characterized in a 6-year-old child with generalized epilepsy. Febrile and unprovoked seizures were present in this child. Both variants were expressed in cis or isolation using human recombinant Cav3.2 calcium channels in tsA-201 cells. Whole-cell patch-clamp recordings indicated that one variant (c.3844C > T; p.R1282W) caused a significant increase in current density consistent with a pathogenic gain-of-function phenotype; while the other cis-related variant (c.5294C > T; p.A1765V) had a benign profile.
\end{abstract}

Keywords: Cav3.2, T-type, Epilepsy, Seizure, Mutation

\section{Introduction}

CACNA1H encodes the $\alpha 1$ pore-forming subunit of the low-voltage activated (LVA) Cav3.2 T-type calcium channel. This channel is known to control neuronal excitability, plays a role in generating rebound burst-firing in thalamic reticular neurons and may contribute to neurotransmitter release at certain CNS synapses [1-3]. A number of missense mutations have been identified in CACNA1H in subjects with different types of generalized epilepsy that include: febrile, myoclonic, temporal lobe, and childhood and juvenile absence epilepsies [4-7]. Pathogenic variants have been identified along the entire length of the Cav3.2 channel sequence, with the most concentrated number of variants being within the intracellular region connecting the first and second transmembrane domain of the channel (see Fig. 1a). Several of these variants have been examined physiologically when expressed in heterologous systems. These studies report that a subset of these epilepsy-associated variants caused gain-of-function mutations, either through increased whole-cell current amplitude or via alterations in the inactivation properties of the channels $[5,8-11]$. Although several reported variants failed to alter channel properties, it is important to remember that dysfunction

\footnotetext{
* Correspondence: zamponi@ucalgary.ca

${ }^{1}$ Department of Physiology and Pharmacology, Alberta Children's Hospital Research Institute, Hotchkiss Brain Institute, Cumming School of Medicine, University of Calgary, 3330 Hospital Dr. NW, Calgary, AB T2N 4N1, Canada Full list of author information is available at the end of the article
}

may be related to the expression patterns of specific splice isoforms. For example, the Genetic Absence Epilepsy Rats from Strasbourg (GAERS) model has altered physiology when these channels contain exon 25, a splice variant transcript that is highly expressed in the thalamus [12]. Moreover, it is possible that mutations may compromise interactions with binding partners such as $\mathrm{HCN}$ channels [13] without affecting channel function per se. Altogether, there is considerable evidence linking Cav3.2 mutations to epilepsy in rodent models and humans.

We report two novel missense variants (p.R1282W and p.A1765V) in the CACNA1H gene that encodes the Cav3.2 channel in a 6-year-old girl with multifocal and primary generalized epilepsy. Electrophysiological evaluations of these two variants in cis and in isolation indicate that the CACNA1H-R1282W mutant mediates gain-of-function properties in Cav3.2 channels.

\section{Materials and methods}

Genetic analysis

Genomic DNA was extracted from blood from the subject and her father. Variants were identified with the Clinical Management Panel for Neurodevelopment Disorders (Courtagen, Woburn, MA).

\section{Molecular cloning and electrophysiology}

QuikChange site-directed mutagenesis kit (Agilent Technologies) was used to insert the two variants in isolation 


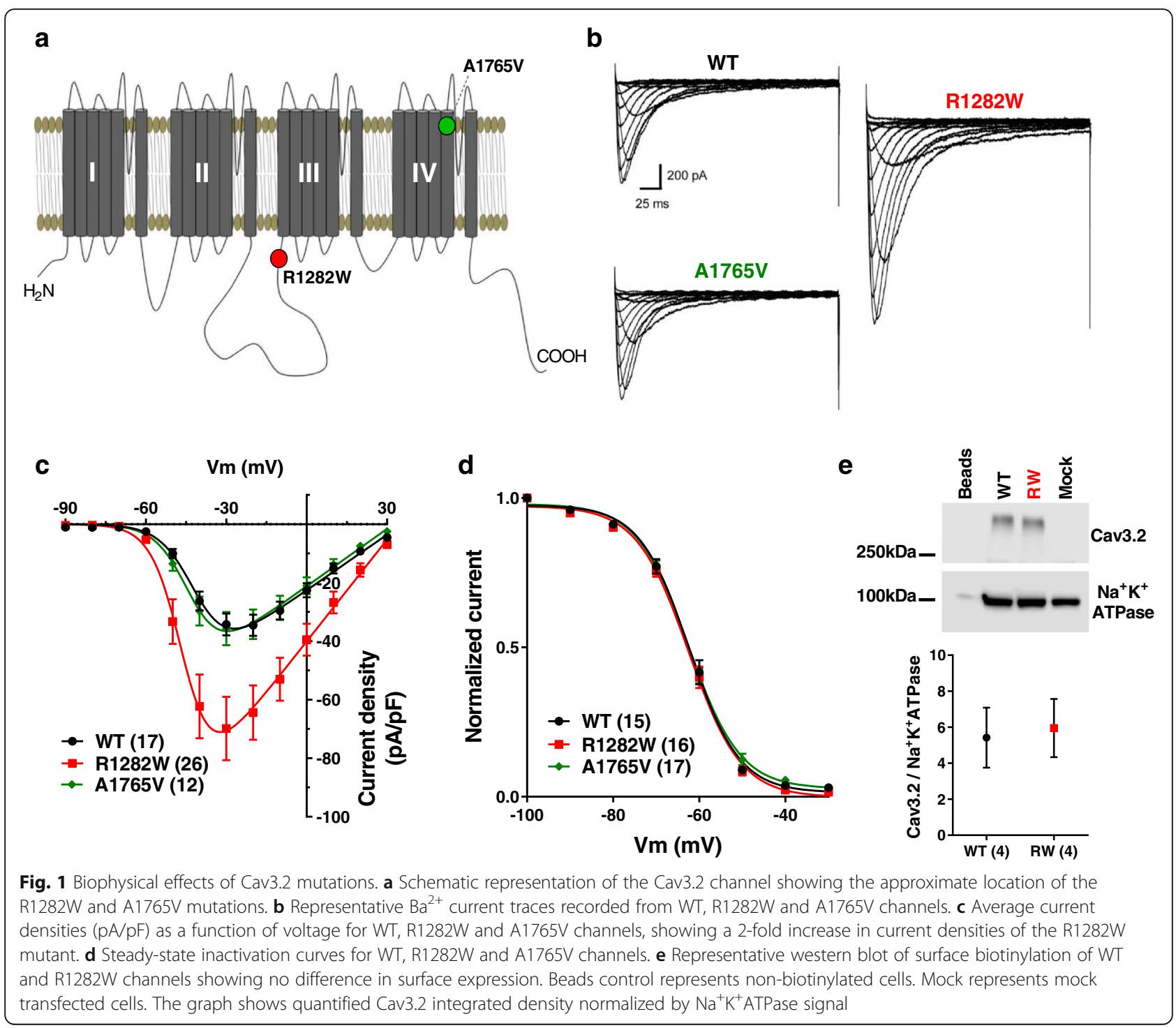

and in cis into the wild-type (WT) human Cav3.2 $\alpha 1$ subunit gene (GenBank: NM_021098.2). The pcDNA3.1 vector was used for expression of the wild-type protein and three types of variants (p.R1282W alone, p.A1765V alone, and both together in cis) in tsA-201 cells.

\section{Cell culture, transfection, and electrophysiology}

Human embryonic kidney tsA-201 cells were cultured and transiently transfected using the calcium phosphate method. Three micrograms of each Cav3.2 cDNA and $0.5 \mu \mathrm{g}$ of eGFP were transfected and cells were grown for $72 \mathrm{~h}$ at $30^{\circ} \mathrm{C}$ (to prevent cell overgrowth) before experiments were carried out. Whole cell patch clamp recordings were performed using an Axopatch 200B amplifier linked to a computer with pCLAMP 9.2 software. The current-voltage relationships were acquired and fitted with a Boltzmann equation as described previously [14].
Whole cell patch clamp recordings were performed at room temperature $\left(22-24^{\circ} \mathrm{C}\right)$ using an Axopatch 200B amplifier linked to a computer with pCLAMP 9.2 software. The external solution contained (in $\mathrm{mM}$ ): $10 \mathrm{BaCl}_{2}$, $125 \mathrm{CsCl}, 1 \mathrm{MgCl}_{2}, 10$ HEPES and 10 Glucose, $\mathrm{pH}$ adjusted to 7.4 with $\mathrm{CsOH}$. The internal pipette solution contained (in $\mathrm{mM}$ ): $130 \mathrm{CsCl}, 2.5 \mathrm{MgCl}_{2}, 10$ HEPES, 5 EGTA, 3 ATP 0.5 GTP, pH 7.4. The current-voltage relationships were acquired and fitted with a Boltzmann equation as described previously [14]. Steady-state inactivation was acquired by applying $1 \mathrm{~s}$ conditioning pulses from 100 to $-30 \mathrm{mV}$ in $10 \mathrm{mV}$ increments followed by a $25 \mathrm{~ms}$ test pulse to $-20 \mathrm{mV}$. Currents were normalized to the maximum current and fitted with a Boltzmann equation. Recovery from inactivation was evaluated by applying two test pulses (P1 and P2) to $-20 \mathrm{mV}$ separated by a varying interval ranging from $10 \mathrm{~ms}$ to $2 \mathrm{~s}$. P2/P1 was plotted as a function of time. Data were analyzed using Clampfit 10.3 
software (Molecular Devices) and fit using GraphPad Prism 6. Averaged data are plotted as mean \pm SE and statistical analysis was performed using Student's $t$ tests, where $p \leq 0.05$ was considered significant.

\section{Results}

\section{Subject}

The subject is a six-year-old female with primary generalized epilepsy and a paternal history of childhood absence epilepsy that resolved "within a few years". The child was born at 33.5 weeks gestation via emergent cesarean section due to maternal pre-eclampsia and had an uncomplicated three-week NICU stay prior to discharge. Her development was normal, with her first words at 10 months and ambulation at 14 months. Her physical and neurological examinations have consistently been within normal limits.

Her first convulsive seizure was at 14 months in the setting of a febrile illness. She had two more febrile convulsive episodes within the next month that were noted to start with right-sided twitching. She had ten additional convulsions in the setting of fever during the following year, most of which were prolonged and required abortive benzodiazepine treatment. She had her first unprovoked generalized tonic-clonic seizure at 2 years of age. The child was then started on Leviteracetam and did well for some time, but developed aggressive behavior and was switched to lamotrigine. She has had no further seizures since starting anti-seizure medications, except in the setting of febrile illnesses.

\section{Neurodiagnostic testing}

Electroencephalogram (EEG) and brain MRI were normal after her first seizures at 17 months. A subsequent EEG after her first unprovoked seizure at 2 years had bilateral multi-focal discharges (right greater than left) arising from the frontal central and anterior temporal regions, along with generalized spike and multispike and slow wave discharges of $3-4 \mathrm{~Hz}$ with bifrontal predominance. At 6 years, another EEG showed frequent generalized $2-2.5 \mathrm{~Hz}$ spike and wave discharges with bifrontal predominance lasting up to $10 \mathrm{~s}$. This EEG was also notable for one episode of behavioral arrest lasting $5 \mathrm{~s}$ during hyperventilation that was associated with a burst of $2.5 \mathrm{~Hz}$ generalized spike and wave discharges (consistent with an absence seizure).

\section{Genetic testing}

Genetic sequencing revealed two paternally-inherited missense variants in the CACNA1H gene (c.3844C > T, p.R1282W and c.5294C > T, p.A1765V) in the same allele. The variant $\mathrm{A} 1765 \mathrm{~V}$, located in the transmembrane region S5 of domain IV (Fig. 1a), had been previously observed in 4 out of 24,702 individuals in the ExAC database (http://exac.broadinstitute.org); while the R1282W variant was located in the cytoplasmic II-III loop (Fig. 1a) and was not found within this database.

\section{Electrophysiology}

Whole-cell patch clamp recordings of Cav3.2 channels containing the variants R1282W and A1765V were compared to wild-type channels (WT). Representative current traces for WT, R1282W and A1765V channels are shown in Fig. 1b. The peak current density recorded from cells expressing R1282W was significantly increased $(p<0.05$, One Way ANOVA followed by Tukey's multiple comparisons test) when compared to WT (Fig. 1c, Table 1). This effect was not due to a change in cell surface expression of the channel as determined by surface biotinylation experiments (Fig. 1e). Neither of the mutations caused a change in steady-state inactivation and recovery from inactivation properties of the channel compared to WT, nor did they affect the half-activation potential (Fig. 1d, Table 1).

The transmembrane A1765V mutant in isolation was similar to WT channels in all of the parameters tested (Fig. 1b-d, Table 1). We also examined possible synergistic effects of the two mutations when placed within the same allele. These experiments showed that A1765V produced no additive effects on current density and activation kinetics to those observed with R1282W alone (Fig. 2a-b); however, the mean half-inactivation voltage was slightly shifted to more a positive potential $(p<0.0001$, Student's t-test) (Fig. 2c-d). This in turn results in an increase in the size of the normalized window current by $15 \%$, overall consistent with a gain of function beyond the increase in whole cell current density. The mechanistic underpinnings of this additive effect on inactivation are unclear.

\section{Discussion}

CACNA1H pathogenic variants have been associated with multiple disorders, including aldosteronism, autism, amyotrophic lateral sclerosis, but is predominantly associated

Table 1 Summary of electrophysiological parameters of wild-type (WT), R1282W and A1765V channels expressed in tsA-201 cells

\begin{tabular}{llllll}
\hline & Peak current density $(\mathrm{pA} / \mathrm{pF})$ & $G \max (\mathrm{nS})$ & $\mathrm{V}_{1 / 2}$ act $(\mathrm{mV})$ & $V_{1 / 2}$ inac $(\mathrm{mV})$ & Trecov $(\mathrm{ms})$ \\
\hline WT & $-34.39 \pm 3.7(17)$ & $0.6 \pm 0.06(17)$ & $-40.94 \pm 0.9(17)$ & $-62.1 \pm 0.9(15)$ & $239.4 \pm 28.5(14)$ \\
R1282W & $-69.8 \pm 10.8(26)^{*}$ & $1.1 \pm 0.15(26)^{*}$ & $-43.5 \pm 1.0(26)$ & $-62.2 \pm 0.8(16)$ & $287.1 \pm 26.9(9)$ \\
A1765V & $-35.7 \pm 5.6(12)$ & $0.6 \pm 0.09(12)$ & $-41.9 \pm 0.9(12)$ & $-62.3 \pm 0.6(17)$ & $259.3 \pm 25.4(11)$ \\
\hline
\end{tabular}

Data are represented as mean \pm SEM. Numbers in parentheses represent number of cells analyzed. * $p<0.05$, One Way ANOVA followed by Tukey's multiple comparison test 
a

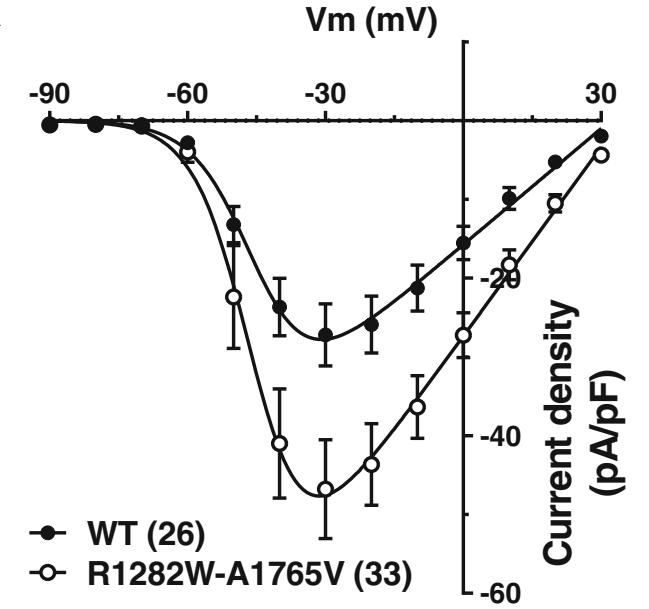

C

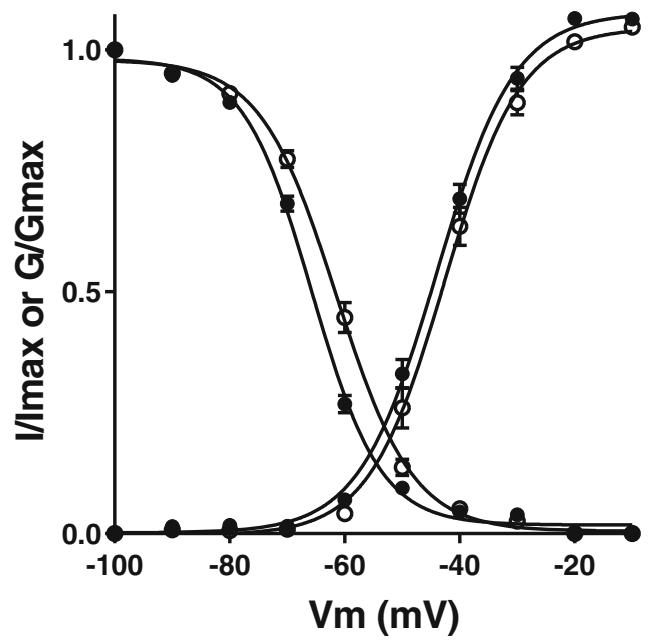

b

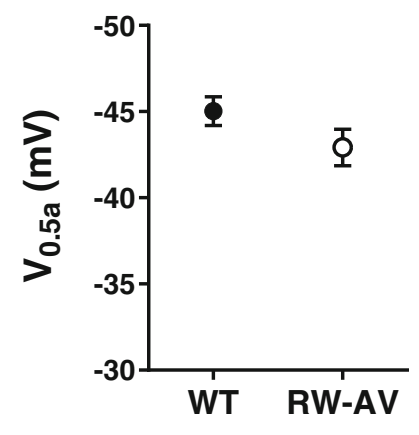

d

Fig. 2 Biophysical analysis of variants R1282W and A1765V in cis. a Average current densities (pA/pF) as a function of voltage for WT and R1282W-A1765V channels, showing an increase in current density for R1282W-A1765V. Numbers in parentheses reflect numbesr of cells. b Mean half-voltage of activation values for R1282W-A1765V compared to WT channels. c Steady-state of inactivation curves for WT and R1282W-A1765V channels. The steady state activation curves extracted from the current-voltage relations in panel (a) are superimposed to highlight the window currents. d Mean half-voltage of inactivation values for R1282W-A1765V compared to WT channels. ${ }^{* * * *} p<0.0001$, Student's t-test

with epilepsy [15-17]. Here, we characterized the functional effects of two missense variants identified in the CACNA1H gene from a patient with epilepsy. These variants were introduced into the Cav3.2 channel isoform that contains the exon 25 , a subtype that is highly expressed in the thalamus [12]. The A1765V mutation alone had no effect on any of the parameters tested and was predicted to be benign by SIFT software analysis (http://sift.bii.a-star.edu.sg). These data and its frequency in the population indicate this may indeed likely be a benign variant. It is important to note that some point mutations found in calcium channels can also behave differently when introduced into different isoforms of the channel [12], when channels are expressed in a different cellular milieu [18], or recorded in different external solutions [14]. Moreover, it has been shown that $\mathrm{T}$-type channels gate much faster at physiological temperatures [19], and it is possible that mutations may affect channel behavior differently at $37^{\circ} \mathrm{C}$ compared to room temperature where we conducted our analysis. In contrast, the R1282W variant was a novel variant that SIFT analysis predicted to potentially alter protein function. When compared to WT Cav3.2 channels, the R1282W-variant was shown to cause a significant 2-fold increase in whole cell current density (Fig. 1b-c, Table 1), consistent with a gain-of-function mutation. Given that cell surface expression was unaltered for this variant, these data indicate that the mutation may have either increased the single channel conductance or the maximum open probability at the plateau of the activation curve. 
T-type channel dysfunction fits well with a pathogenic model of this disorder as they are important for the thalamocortical network, where they contribute to generation of bursts of action potentials and network oscillations [2]. Therefore, an increase in T-type channel activity can shift the balance between excitatory and inhibitory neurotransmission and increase seizure susceptibility. This is also supported by genetic rodent models of epilepsy, such as GAERS and the Wistar Albino Glaxo Rats from Rijswijk (WAG/Rij), which exhibit an increase in T-type channel function in nRT neurons $[20,21]$. However, although certain mutations in Cav3.2 channels have been previously associated with an increased incidence of febrile seizures [5], this may not necessarily involve a dysfunction of the thalamocortical network. Importantly, T-type calcium channels are prominently expressed in other brain structures that are linked to febrile seizure disorders, including the hippocampus, and have been shown to play an important role in generating seizure activity in this brain region [22-26].

The impact of variants identified in patients with different disorders can be very difficult to predict without the functional analysis of the affected proteins. The increase in availability of high through-put sequencing data have provided numerous examples where functional analysis is important to confirm pathogenicity in rare disorders in which some potentially pathogenic variants are found to be quite common in the general unaffected population and therefore likely benign [27]. This becomes an even greater challenge when studying complex diseases such as epilepsy, which may have polygenic and/or multifactorial origins. Many variants identified in the CACNA1H gene have shown little physiological alterations when tested in vitro and are not considered sufficiently pathogenic to cause epilepsies on their own $[5,9]$; however, they are believed to act in combination with variants in other susceptibility genes and/or environmental factors to raise the level of neuronal excitability and generate seizures [28]. In addition, it is possible that even small changes in electrophysiological properties of Cav3.2 channels may affect downstream signaling processes such as calcium-dependent gene transcription, which in turn may lead to the dysregulation of pathways that culminate in increased seizure susceptibility. In summary, a functional analysis of these two cis-linked variants revealed that only one of them caused a novel pathogenic gain-of-function (R1282W) mutation in $C A C N A 1 H$, while the other variant seems likely benign.

\section{Abbreviations}

EEG: Electroencephalogram; NICU: Neonatal intensive care unit; nRT: nucleus reticularis

\section{Acknowledgments}

We thank the patient and family members for their contribution to this study. We are grateful to Lina Chen for her technical support. This work was supported by a grant from the Canadian Institutes of Health Research (CIHR) to GWZ. MAG is supported by a CIHR Fellowship. GWZ is a Canada Research Chair in Molecular Neuroscience. IAS was supported by a Fellowship from the Savoy Foundation. TMP was funded by the Cedars-Sinai Diana and Steve Marienhoff Fashion Industries Guild Endowed Fellowship in Pediatric Neuromuscular Diseases and the Fashion Industries Guild Endowed Fellowship in Undiagnosed Diseases.

\section{Authors' contributions}

IAS and TMP contributed to the design, acquisition and analysis of data and writing of the manuscript. MAG contributed to the design, acquisition and analysis of data. FXZ contributed to the acquisition of data. WGM, JM, JL provided clinical evaluation and EEG analysis. GWZ contributed to the conception and writing of the manuscript and supervised the study. All authors read and approved the final manuscript.

\section{Funding}

This work was supported by a grant to GWZ from the Canadian Institutes of Health Research (CIHR). GWZ holds a Canada Research Chair. MA was supported by a Fellowship from Alberta Innovates and holds a CIHR Postdoctoral Fellowship.

\section{Availability of data and materials}

The data used in our study are available from the authors on reasonable request

Ethics approval and consent to participate

Protocols were approved through the Cedars-Sinai Medical Center (CSMC) Institutional Review Boards (Pro00037131) and the family gave informed consent.

\section{Consent for publication}

Not applicable.

\section{Competing interests}

The authors declare that they have no competing interests.

\section{Author details}

${ }^{1}$ Department of Physiology and Pharmacology, Alberta Children's Hospital Research Institute, Hotchkiss Brain Institute, Cumming School of Medicine, University of Calgary, 3330 Hospital Dr. NW, Calgary, AB T2N 4N1, Canada. ${ }^{2}$ Neurology Division, Children's Hospital Los Angeles \& Department of Neurology, Keck School of Medicine of University of Southern California, Los Angeles, USA. ${ }^{3}$ Department of Pediatrics, Division of Pediatric Neurology, David Geffen School of Medicine at UCLA, Los Angeles, CA, USA. ${ }^{4}$ Department of Pediatrics, Cedars-Sinai Medical Center, Los Angeles, CA, USA. ${ }^{5}$ Department of Neurology, Cedars-Sinai Medical Center, Los Angeles, CA, USA. 'Board of Governors Regenerative Medicine Institute, Cedars-Sinai Medical Center, Los Angeles, CA, USA.

Received: 28 August 2019 Accepted: 2 October 2019

Published online: 24 October 2019

\section{References}

1. Leresche N, Lambert RC. T-type calcium channels in synaptic plasticity. Channels (Austin). 2017;11:121-39. https://doi.org/10.1080/19336950.2016.1238992.

2. Perez-Reyes E. Molecular physiology of low-voltage-activated t-type calcium channels. Physiol Rev. 2003;83:117-61. https://doi.org/10.1152/physrev.00018.2002.

3. Zamponi GW. Targeting voltage-gated calcium channels in neurological and psychiatric diseases. Nat Rev Drug Discov. 2016;15:19-34. https:// doi.org/10.1038/nrd.2015.5.

4. Cain SM, Snutch TP. T-type calcium channels in burst-firing, network synchrony, and epilepsy. Biochim Biophys Acta. 1828;2013:1572-8. https:// doi.org/10.1016/j.bbamem.2012.07.028.

5. Heron SE, Khosravani H, Varela D, Bladen C, Williams TC, Newman MR, Scheffer IE, Berkovic SF, Mulley JC, Zamponi GW. Extended spectrum of idiopathic generalized epilepsies associated with CACNA1H functional variants. Ann Neurol. 2007;62:560-8. https://doi.org/10.1002/ana.21169.

6. Zamponi GW, Lory P, Perez-Reyes E. Role of voltage-gated calcium channels in epilepsy. Pflugers Arch. 2010;460:395-403. https://doi.org/ 10.1007/s00424-009-0772-x 
7. Chen Y, Lu J, Pan H, Zhang Y, Wu H, Xu K, Liu X, Jiang Y, Bao X, Yao Z, Ding K, Lo WH, Qiang B, Chan P, Shen Y, Wu X. Association between genetic variation of CACNA1H and childhood absence epilepsy. Ann Neurol. 2003; 54:239-43. https://doi.org/10.1002/ana.10607.

8. Khosravani H, Altier C, Simms B, Hamming KS, Snutch TP, Mezeyova J, McRory JE, Zamponi GW. Gating effects of mutations in the Cav3.2 T-type calcium channel associated with childhood absence epilepsy. J Biol Chem. 2004;279:9681-4. https://doi.org/10.1074/jbc.C400006200.

9. Peloquin JB, Khosravani H, Barr W, Bladen C, Evans R, Mezeyova J, Parker D, Snutch TP, MCRory JE, Zamponi GW. Functional analysis of Ca3.2 T-type calcium channel mutations linked to childhood absence epilepsy. Epilepsia. 2006;47:655-8. https://doi.org/10.1111/j.1528-1167.2006.00482.x.

10. Vitko I, Chen Y, Arias JM, Shen Y, Wu XR, Perez-Reyes E. Functional characterization and neuronal modeling of the effects of childhood absence epilepsy variants of CACNA1H, a T-type calcium channel. J Neurosci. 2005;25:4844-55. https://doi.org/10.1523/JNEUROSCI.0847-05.2005.

11. Vitko I, Bidaud I, Arias JM, Mezghrani A, Lory P, Perez-Reyes E. The I-II loop controls plasma membrane expression and gating of Ca(v)3.2 T-type Ca2+ channels: a paradigm for childhood absence epilepsy mutations. J Neurosci. 2007;27:322-30. https://doi.org/10.1523/JNEUROSCl.1817-06.2007.

12. Powell KL, Cain SM, Ng C, Sirdesai S, David LS, Kyi M, Garcia E, Tyson JR, Reid CA, Bahlo M, Foote SJ, Snutch TP, O'Brien TJ. A Cav3.2 T-type calcium channe point mutation has splice-variant-specific effects on function and segregates with seizure expression in a polygenic rat model of absence epilepsy. J Neurosci. 2009;29:371-80. https://doi.org/10.1523/JNEUROSCI.5295-08.2009.

13. Fan J, Gandini MA, Zhang FX, Chen L, Souza IA, Zamponi GW. Down-regulation of T-type Cav3.2 channels by hyperpolarization-activated cyclic nucleotide-gated channel 1 (HCN1): Evidence of a signaling complex. Channels (Austin). 2017;11: 434-43. https://doi.org/10.1080/19336950.2017.1326233.

14. Souza IA, Gandini MA, Wan MM, Zamponi GW. Two heterozygous Cav3.2 channel mutations in a pediatric chronic pain patient: recording conditiondependent biophysical effects. Pflugers Arch. 2016;468:635-42. https://doi. org/10.1007/s00424-015-1776-3.

15. Scholl UI, Stolting G, Nelson-Williams C, Vichot AA, Choi M, Loring E, Prasad ML, Goh G, Carling T, Juhlin CC, Quack I, Rump LC, Thiel A, Lande M, Frazier BG, Rasoulpour M, Bowlin DL, Sethna CB, Trachtman H, Fahlke C, Lifton RP. Recurrent gain of function mutation in calcium channel CACNA1H causes early-onset hypertension with primary aldosteronism. Elife. 2015;4:e06315. https://doi.org/10.7554/eLife.06315.

16. Splawski I, Yoo DS, Stotz SC, Cherry A, Clapham DE, Keating MT. CACNA1H mutations in autism spectrum disorders. J Biol Chem. 2006;281:22085-91. https://doi.org/10.1074/jbc.M603316200.

17. Rzhepetskyy Y, Lazniewska J, Blesneac I, Pamphlett R, Weiss N. CACNA1H missense mutations associated with amyotrophic lateral sclerosis alter Cav3.2 T-type calcium channel activity and reticular thalamic neuron firing. Channels (Austin). 2016;10:466-77. https://doi.org/10.1080/19336950.2016.1204497.

18. Hans M, Luvisetto S, Williams ME, Spagnolo M, Urrutia A, Tottene A, Brust PF, Johnson EC, Harpold MM, Stauderman KA, Pietrobon D. Functional consequences of mutations in the human alpha1 A calcium channel subunit linked to familial hemiplegic migraine. J Neurosci. 1999;19:1610-9.

19. Iftinca M, McKay BE, Snutch TP, McRory JE, Turner RW, Zamponi GW. Temperature dependence of T-type calcium channel gating. Neuroscience. 2006;142:1031-42. https://doi.org/10.1016/j.neuroscience.2006.07.010.

20. Tsakiridou E, Bertollini L, de Curtis M, Avanzini G, Pape HC. Selective increase in T-type calcium conductance of reticular thalamic neurons in a rat model of absence epilepsy. J Neurosci. 1995;15:3110-7.

21. Broicher T, Kanyshkova T, Meuth P, Pape HC, Budde T. Correlation of Tchannel coding gene expression, IT, and the low threshold Ca2+ spike in the thalamus of a rat model of absence epilepsy. Mol Cell Neurosci. 2008;39: 384-99. https://doi.org/10.1016/j.mcn.2008.07.012.

22. Su H, Sochivko D, Becker A, Chen J, Jiang Y, Yaari Y, Beck H. Upregulation of a T-type Ca2+ channel causes a long-lasting modification of neuronal firing mode after status epilepticus. J Neurosci. 2002;22:3645-55. 20026339.

23. Yaari Y, Yue C, Su H. Recruitment of apical dendritic T-type Ca2+ channels by backpropagating spikes underlies de novo intrinsic bursting in hippocampal epileptogenesis. J Physiol. 2007;580:435-50. https://doi.org/10. 1113/jphysiol.2007.127670.

24. Becker AJ, Pitsch J, Sochivko D, Opitz T, Staniek M, Chen CC, Campbell KP, Schoch S, Yaari Y, Beck H. Transcriptional upregulation of Cav3.2 mediates epileptogenesis in the pilocarpine model of epilepsy. J Neurosci. 2008;28: 13341-53. https://doi.org/10.1523/JNEUROSCI.1421-08.2008.
25. Kim CH. Cav3.1 T-type calcium channel modulates the epileptogenicity of hippocampal seizures in the kainic acid-induced temporal lobe epilepsy model. Brain Res. 2015;1622:204-16. https://doi.org/10.1016/j.brainres.2015.06.015.

26. Dube CM, Brewster AL, Baram TZ. Febrile seizures: mechanisms and relationship to epilepsy. Brain and Development. 2009;31:366-71. https:// doi.org/10.1016/j.braindev.2008.11.010.

27. Walsh R, Thomson KL, Ware JS, Funke BH, Woodley J, McGuire KJ, Mazzarotto F, Blair E, Seller A, Taylor JC, Minikel EV, Exome Aggregation C, MacArthur DG, Farrall M, Cook SA, Watkins H. Reassessment of Mendelian gene pathogenicity using 7,855 cardiomyopathy cases and 60,706 reference samples. Genet Med. 2017;19:192-203. https://doi.org/10.1038/gim.2016.90.

28. Dibbens LM, Heron SE, Mulley JC. A polygenic heterogeneity model for common epilepsies with complex genetics. Genes Brain Behav. 2007;6:593-7. https://doi.org/10.1111/j.1601-183X.2007.00333.x.

\section{Publisher's Note}

Springer Nature remains neutral with regard to jurisdictional claims in published maps and institutional affiliations.
Ready to submit your research? Choose BMC and benefit from:

- fast, convenient online submission

- thorough peer review by experienced researchers in your field

- rapid publication on acceptance

- support for research data, including large and complex data types

- gold Open Access which fosters wider collaboration and increased citations

- maximum visibility for your research: over $100 \mathrm{M}$ website views per year

At BMC, research is always in progress.

Learn more biomedcentral.com/submissions 